\title{
CONTRIBUTIONS OF INFORMATION TECHNOLOGIES TO LAST PLANNER SYSTEM IMPLEMENTATION
}

\author{
Camilo Ignacio Lagos ${ }^{1}$, Rodrigo Fernando Herrera ${ }^{2}$, and Luis Fernando Alarcón ${ }^{3}$
}

\begin{abstract}
The Last Planner System (LPS) has been in use for over 20 years; however, some of its components remain at a basic level of implementation. This paper seeks to identify improvements in the level of implementation of those components with the use of Information Technologies (IT). In addition, correlation analysis between those components and the Plan Percent Complete (PPC) was performed to determine which components aided by IT use are correlated to the PPC.

Results were obtained from a sample of 18 construction projects in which the level of implementation of 16 LPS components and their PPC were measured. Results showed that the group of 10 IT supported projects had a significant improvement in 6 of the components and in the overall level of implementation of the methodology. Also, correlative analysis between the level of implementation of each component and the PPC allowed to identify a positive correlation between 7 components and the PPC, and between the overall implementation level and the PPC. Finally, two components were found to be both correlated to the PPC and improved using IT. These components are the standardisation of the planning and control process, as well as the analysis and systematic removal of constraints.
\end{abstract}

Keywords: Last Planner System, Information Technologies, Implementation Level.

\section{INTRODUCTION}

\subsection{Context}

The Last Planner System (LPS) has been in use for over 20 years in multiple countries and projects with highly beneficial impacts on project performance (Ballard and Howell 2003). A recent study reveals that even though the level of implementation of the majority of its components has improved over the years, the adoption of some components remains at a basic level (Daniel et al. 2015). While components related to short term planning are reported to be widely and extensively adopted, the use of the Executable Work Inventory (EWI), Constraints Management, Root Cause Analysis and Corrective Actions Management are still the least implemented parts of the methodology (Daniel et al. 2015; Salvatierra et al. 2015; Lagos et al. 2016).

\subsection{Problem}

The insufficient degree of implementation of the aforementioned components prevents the complete use of the LPS potential (Lagos et al. 2016). Moreover, previous research carried

$1 \quad$ Msc student, Department of Construction Engineering and Management, Pontificia Universidad Católica de Chile, Researcher - GEPUC, Santiago, Chile, clagos@gepro.cl

$2 \mathrm{PhD}$ student, Department of Construction Engineering and Management, Pontificia Universidad Católica de Chile, Professor School of Civil Engineering, Pontificia Universidad Católica de Valparaíso, Chile, Researcher - GEPUC, Santiago, Chile, rodrigo.herrera@pucv.cl

3 Professor, Department of Construction Engineering and Management, Pontificia Universidad Católica de Chile, Santiago, Chile, lalarcon@ing.puc.cl 
out by the Production Management Centre of the Catholic University of Chile (GEPUC) found that the adoption of components such as Lookahead Planning, Constraints Management and use of the EWI was highly correlated to improvements in performance indicators like the PPC (Alarcón et al. 2005). Therefore, improving and standardizing the adoption of the remaining LPS components should be one of the main objectives of the continual improvement of the methodology and its implementation (Daniel et al. 2015).

\subsection{Opportunity}

Evidence also shows that the use of Information Technologies Systems (IT), based on LPS, to support its implementation resulted in a more comprehensive implementation of the methodology and better performance (Alarcón and Calderón 2003; Alarcón et al. 2005), even though the use of IT systems is not yet fully adopted by the industry. For example, previous research of the use of IMPERA, which is a support system developed by GEPUC that has been used in more than 100 projects for over 15 years (Alarcón and Calderón 2003; Alarcón et al. 2005; Cisterna 2013; Alarcón et al. 2014; Lagos et al. 2016), shows that the majority of the projects used only about $40 \%$ of the software capabilities (Cisterna 2013).

Nonetheless, GEPUC has continuously developed IMPERA, including reports and contributions related to the less used components of the methodology and software itself. These contributions have already been proven to benefit the collection and use of information regarding constraints, causes of non-compliances (CNCs) and corrective actions (Lagos et al. 2016). Since the management of information regarding the aforementioned components is improved by the use of the IT system, it could be inferred that their degree of implementation has also benefited. Therefore, the first aim of this paper is to analyse the effect of the use of IT Systems on the level of implementation of the methodology and its least adopted components.

In addition, since previous research has identified a correlation between LPS level of implementation and the PPC (Alarcón et al. 2005), the second aim of this paper is to identify which are the components positively correlated to the PPC. Finally, the third objective is to demonstrate that there are in fact components correlated to the PPC that have significant improvements with the use of IT systems, allowing to conclude that IT support can improve both implementation and performance in LPS.

\subsection{Research questions}

The first question addressed in this research is: Which LPS components have significant improvements in their level of implementation by the use of IT support? This will allow us to determine whether the use of IT systems can improve the level of implementation of LPS and what components are most benefited by its use. The second question is: What LPS components present a significant correlation between their level of implementation and the PPC? This will allow us to determine components of the methodology where improvements can beneficially impact project performance. Finally, the conjoint analysis of the answers to both questions can help conclude if the use of the IT System addressed allows an improvement in LPS components significantly correlated with project performance and the fulfilment of commitments.

\section{MEthodology}

The research methodology seeks to answer the research questions, as follows: 
1. Literature review regarding the Last Planner System (LPS) and its level of implementation.

2. Create and validate an instrument to assess the level of implementation of LPS in the construction stage.

3. Collect information about the level of implementation and traditional indicators of LPS in 18 construction projects.

4. Data analysis and discussion of results: frequencies analysis, correlations test and Mann-Whitney U test.

To create and validate the tool to evaluate the level of LPS implementation, the Planning Best Practices (PBP) (Bernades and Formoso 2002; Viana et al. 2010) tool and a deep literature review were used as a basis. In addition, user and expert criteria were considered to develop a metric that details the fundamental aspects of each proposed component by PBP, described in such a way as to facilitate self-evaluation by users. This metric was validated qualitatively by a panel of 6 experts.

The instrument consists of 16 criteria, with n sub criteria for each of them (Table 1). The degree of implementation of each sub-criterion on a Likert scale is evaluated with the following levels: non-existent (0), low (1), moderately (2) and complete (3).

Then, for each criterion, an average compliance percentage (Equation 1) is calculated; finally the level of LPS implementation is calculated with the average of the percentage of each criterion.

$$
\text { Criteria accomplishment }=\sum_{k=1}^{n} \frac{\text { Score sub criteria }_{k}}{\text { number of sub criteria }}
$$

The instrument was applied to 18 construction projects that were applying the Last Planner System (LPS). All projects assessed had completed a 4 month implementation by LPS consultants. To ensure the quality of data, each project was assessed by the consultant in charge of the implementation. An analysis of reliability of the instrument was performed by calculating Cronbach's alpha, which in this case gave a value of 0.924 ; this demonstrates a high reliability of the constructed instrument (Hernández et al. 2006).

During the execution of these eighteen projects, in addition to assessing the level of LPS implementation, the LPS indicator PPC was weekly measured. Ten of eighteen projects used the addressed software to support LPS and to carry out all phases of the planning and control process.

To answer the research question about the correlation between the level of implementation and the PPC, we used the Pearson correlation coefficient. Also, we correlated the PPC with each of the instrument criteria presented in Table 1.

To answer the research question about whether there are differences between the level of implementation of LPS in the project with IT support and the project without this software, the Mann-Whitney $U$ test technique was used to verify globally and for each criterion; therefore, the following hypothesis formulation as made:

$\mathrm{H} 0=$ There is no difference in the LPS level implementation between projects with IT support and projects with traditional support regarding the criteria i.

H1: There is a difference in the LPS level implementation between projects with IT support and projects with traditional support regarding the criteria i.

A significance level of 0.05 is defined and the p-value for each face of the criteria for whether we were with $\mathrm{H} 0$ or $\mathrm{H} 1$ hypothesis was obtained. If the p-value is greater than the significance level, we cannot reject the null hypothesis; and on the other hand if the 
p-value is less than the significance level, we can reject the null hypothesis and we can stay with $\mathrm{H} 1$.

Table 1: Number of sub criteria for each criterion.

\begin{tabular}{cc}
\hline Criteria & $\begin{array}{c}\text { Number of } \\
\text { sub criteria }\end{array}$ \\
\hline $\begin{array}{c}\text { Standardisation of the planning and control process } \\
\text { Standardisation of short-term planning meetings }\end{array}$ & 5 \\
Participation of the last planners in planning and decision-making meeting & 5 \\
Use of indicators to assess compliance with planning & 6 \\
Critical analysis of information & 8 \\
Visual information management & 5 \\
Correct definition of work packages & 4 \\
Phase Planning & 4 \\
Using an easy-to-understand and transparent master plan & 4 \\
Standardisation of intermediate planning & 6 \\
Systematic analysis and removal of constrains & 5 \\
Using an Executable Work Inventory (EWI) & 2 \\
Exclusive use of EWI in short-term planning & 4 \\
Planning and control of physical work flows & 5 \\
Corrective actions based on causes of non-compliance & 6 \\
Communication and teamwork & 5
\end{tabular}

\section{ANALYSIS AND RESULTS}

\subsection{Improvement of the level of implementation of LPS components with IT support}

The hypothesis tests at the global level obtained a p-value of 0.02 , which means that the null hypothesis can be rejected. Therefore, it is possible to conclude that there is a significant difference in the level of LPS implementation for projects that use the IT system to support the methodology, compared to projects with traditional support. In fact, a $22 \%$ increment in the general level of implementation of the methodology was detected in the IT aided group. Detailed results are presented in Table 2.

In addition, when reviewing the Mann Whitney $U$ test at each criterion, significant differences were identified in 5 of the components. This means that even though the average by component for the IT aided group was at least $10 \%$ higher in 10 out of the 16 criterions, 5 components were found to be significantly aided by the use of IT. These components were on average improved by $40 \%$. However, it is important to mention that even though the use of the EWI did not fulfil the p-value criteria for selection, it obtained an $85 \%$ measured increase in the IT aided group, which allows us to infer that the benefit 
of the use of IT systems for this component might also be validated with a more extensive study.

Table 2: Results of the Mann Whitney U test for independent samples.

\begin{tabular}{|c|c|c|c|c|}
\hline Criteria & $\begin{array}{l}\text { Traditional } \\
\text { Support }\end{array}$ & $\begin{array}{c}\text { IT } \\
\text { Support }\end{array}$ & $\begin{array}{l}\text { Percentage } \\
\text { difference }\end{array}$ & $\begin{array}{c}\mathrm{p}- \\
\text { value }\end{array}$ \\
\hline $\begin{array}{c}\text { Standardisation of the planning and control } \\
\text { process }\end{array}$ & 1,45 & 2,16 & $49 \%$ & 0,02 \\
\hline Standardisation of short-term planning meetings & 2,44 & 2,40 & $-2 \%$ & 0,82 \\
\hline $\begin{array}{l}\text { Participation of the last planners in planning and } \\
\text { decision-making meeting }\end{array}$ & 1,70 & 1,74 & $2 \%$ & 1,00 \\
\hline $\begin{array}{l}\text { Use of indicators to assess compliance with } \\
\text { planning }\end{array}$ & 1,90 & 2,57 & $35 \%$ & 0,02 \\
\hline Critical analysis of information & 1,06 & 1,75 & $65 \%$ & 0,00 \\
\hline Visual information management & 1,90 & 2,12 & $12 \%$ & 0,19 \\
\hline Correct definition of work packages & 2,75 & 2,70 & $-2 \%$ & 0,01 \\
\hline $\begin{array}{l}\text { Using an easy-to-understand and transparent } \\
\text { master plan }\end{array}$ & 2,06 & 2,55 & $24 \%$ & 0,01 \\
\hline Phase Planning & 1,38 & 1,75 & $27 \%$ & 0,30 \\
\hline Standardisation of intermediate planning & 1,98 & 2,20 & $11 \%$ & 0,16 \\
\hline Systematic analysis and removal of constrains & 1,93 & 2,42 & $26 \%$ & 0,02 \\
\hline Using an Executable Work Inventory (EWI) & 0,81 & 1,50 & $85 \%$ & 0,06 \\
\hline Exclusive use of EWI in short-term planning & 1,53 & 1,78 & $16 \%$ & 0,30 \\
\hline Planning and control of physical work flows & 2,23 & 2,40 & $8 \%$ & 0,36 \\
\hline $\begin{array}{l}\text { Corrective actions based on causes of non- } \\
\text { compliance }\end{array}$ & 1,69 & 1,70 & $1 \%$ & 0,89 \\
\hline Communication and teamwork & 2,35 & 2,42 & $3 \%$ & 0,86 \\
\hline Average & 1,82 & 2,13 & $22 \%$ & 0,02 \\
\hline
\end{tabular}

Finally, components with a significant improvement were: standardisation of the planning and control process; use of indicators to assess compliance with planning; critical analysis of information; correct definition of work packages; using an easy-to-understand and transparent master plan; and systematic analysis and removal of constraints. All but the correct definition of work packages observed an improvement of at least $24 \%$.

\subsection{Correlation between LPS implementation and the PPC}

The correlation analysis performed between the PPC and the level of implementation of the methodology allowed us to observe a positive relationship between the general degree of implementation and the fulfilment of commitments, represented by a Pearson Coefficient of 0.7. In addition, analysis by criterion allowed us to determine positive correlations between 7 components and the PPC. These components are the standardisation of the planning and control process; participation of the last planners in planning and decision-making meeting; standardisation of intermediate planning; 
systematic analysis and removal of constraints; exclusive use of EWI in short-term planning; corrective actions based on causes of non-compliance; and communication and teamwork. Results of the correlation analyses are presented in Table 3.

Table 3: Correlation between LPS components and PPC.

\begin{tabular}{cc}
\hline Criteria & $\begin{array}{c}\text { Pearson } \\
\text { Coefficient }\end{array}$ \\
\hline Standardisation of the planning and control process & 0,5 \\
Standardisation of short-term planning meetings & 0,4 \\
Participation of the last planners in planning and decision-making meeting & 0,6 \\
Use of indicators to assess compliance with planning & 0,1 \\
Critical analysis of information & 0,1 \\
Visual information management & 0,4 \\
Correct definition of work packages & 0,0 \\
Psing an easy-to-understand and transparent master plan & 0,2 \\
Standardisation of intermediate planning & 0,1 \\
Systematic analysis and removal of constrains & 0,7 \\
Using an Executable Work Inventory (EWI) & 0,5 \\
Exclusive use of EWI in short-term planning & 0,4 \\
Planning and control of physical work flows & 0,8 \\
Corrective actions based on causes of non-compliance & 0,4 \\
Communication and teamwork & 0,7 \\
General level of implementation & 0,7 \\
\hline Pang & 0,7
\end{tabular}

Then the average level of implementation was calculated for each component and the projects were separated into a group composed only of projects below average for a specific criterion and a group of projects above average. Then the average PPC of each group was calculated for each of the 7 components that resulted correlated to the PPC and for the general level of implementation. Results, which are presented in Table 4, allow us to observe PPC differences between the projects below and above average in each component.

\subsection{Conjoint analysis of results}

First, it was possible to conclude that projects with IT support have a higher general level of implementation of LPS, which is also correlated to the PPC. This means that the use of IT can potentially help projects improve their weekly accomplishment of commitments. In addition, two of the components significantly correlated to the PPC were also significantly improved by the use of the IT software. These components are the Standardisation of the planning and control process as well as the analysis and systematic removal of constraints. Hence, it can be inferred that the use of IT support for LPS implementations implies the adoption of practices that result in better accomplishment of short-term plans. 
Table 4: PPC difference in projects above and below average level of implementation of significantly correlated components.

\begin{tabular}{cccc}
\hline Criteria & $\begin{array}{c}\text { PPC of projects } \\
\text { above average } \\
\text { level of } \\
\text { implementation }\end{array}$ & $\begin{array}{c}\text { PPC of projects } \\
\text { below average } \\
\text { level of } \\
\text { implementation }\end{array}$ & $\begin{array}{c}\text { Percentage } \\
\text { difference }\end{array}$ \\
\hline $\begin{array}{c}\text { Standardisation of the planning and } \\
\text { control process }\end{array}$ & $71 \%$ & $66 \%$ & $5 \%$ \\
$\begin{array}{c}\text { Participation of the last planners in } \\
\text { planning and decision-making } \\
\text { meeting }\end{array}$ & $71 \%$ & $65 \%$ & $6 \%$ \\
$\begin{array}{c}\text { Standardisation of intermediate } \\
\text { planning }\end{array}$ & $72 \%$ & $65 \%$ & $7 \%$ \\
$\begin{array}{c}\text { Systematic analysis and removal of } \\
\text { constrains }\end{array}$ & $71 \%$ & $64 \%$ & $7 \%$ \\
$\begin{array}{c}\text { Corrective actions based on causes } \\
\text { of non-compliance }\end{array}$ & $73 \%$ & $65 \%$ & $8 \%$ \\
$\begin{array}{c}\text { Communication and teamwork } \\
\text { Exclusive use of EWI in short-term } \\
\text { planning } \\
\text { Average }\end{array}$ & $72 \%$ & $63 \%$ & $9 \%$ \\
\hline
\end{tabular}

\section{CONCLUSIONS}

In first place, if IT systems are used to support LPS, greater implementation standards are achieved globally, and specifically in the following elements: standardisation of the planning and control process; use of indicators to assess compliance with planning; critical analysis of information; using an easy-to-understand and transparent master plan; and analysis and systematic removal of constraints. Secondly, the degree of LPS implementation is positively correlated with the PPC, specifically for the following components: standardisation of the planning and control process; participation of the last planners in LPS meetings; standardisation of intermediate planning; systematic analysis and removal of constraints; exclusive use of EWI; corrective actions based on CNCs; as well as communication and teamwork.

When we link the results of the analyses performed, we can distinguish two critical components: standardisation of the planning and control process and the systematic analysis and removal of constraints. Standardization is only achieved by improving communication, analysis and knowledge management. Hence, IT systems must focus not only on operational matters but have a systemic approach to LPS implementation. Finally, work preparation can also be improved by the facilitation of communication and information management through continual development of IT tools. 


\section{ACKNOWLEDGMENTS}

We want to thank to GEPUC and GEPRO that provided access to data collection for this study. Rodrigo F. Herrera acknowledges financial support for PhD studies from VRI of Pontifical Catholic University of Chile.

\section{REFERENCES}

Alarcón, L. F. and Calderón, R. (2003) 'A production planning support system for construction projects', 11th Annual Conference of the International Group for Lean Construction. Virginia, USA.

Alarcón, L. F., Diethelm, S., Rojo, Ó. and Calderon, R. (2005) 'Assessing the impacts of implementing lean construction', 13th International Group for Lean Construction Conference, IGLC 13, July 19, 2005 - July 21, 2005, pp. 387-393.

Alarcón, L. F., Salvatierra, J. L. and Letelier, J. A. (2014) 'Using Last Planner Indicators To Identify Early Signs Of Project Performance', Proceedings for the 22th Annual Conference of the International Group for Lean Construction, pp. 547-558.

Ballard, G. and Howell, G. (2003) 'An update on last planner', 11th Annual Conference of the International Group for Lean Construction, pp. 1-10.

Bernardes, M. and Formoso, C. (2002) 'Contributions To the Evaluation of Production Planning and Control Systems in Building Companies', 10th Annual Conference of the International Group for Lean Construction. Gramado, Brazil, pp. 1-11.

Cisterna, D. (2013) Desarrollo y evaluación de indicadores de control para implementación en software de planificación y control de proyectos basado en metodología Last Planner. Universidad de Chile.

Daniel, E. I., Pasquire, C. and Dickens, G. (2015) 'Exploring the Implementation of the Last Planner® System Through Iglc Community: Twenty One Years of Experience’, (February 2016), pp. 153-162.

Hernández, R., Fernández, C. and Baptista, P. (2006) Metodología de la investigación, McGraw-Hill Interamericana. México D.F.

Lagos, C., Alarcón, L. F. and Salvatierra, J. L. (2016) 'Improving the Use of Information Management for Continuous Improvement With the Last Planner System', Memorias del VII Elagec, Bogotá, Colombia, pp. 737-745.

Salvatierra, J. L., Alarcón, L. F., López, Á. and Velásquez, X. (2015) 'Lean diagnosis for Chilean construction industry: Towards more sustainable Lean practices and tools', Proceedings for the 23th Annual Conference of the International Group for Lean Construction, pp. 642-651.

Viana, D., Mota, B., Formoso, C., Echeveste, M., Peixoto, M. and Rodrigues, C. (2010) 'A survey on the last planner system: Impacts and difficulties for implementation in Brazilian companies', Proceedings for the 18th Annual Conference of the International Group for Lean Construction, pp. 497-507. 